\title{
Compact reduction in Lipschitz-free spaces - RETRACTION
}

\author{
Ramón J. Aliaga (1) \\ Universitat Politècnica de València, Instituto Universitario de \\ Matemática Pura y Aplicada, Camino de Vera S/N, 46022, Valencia, \\ Spain

\section{Camille Noûs} \\ Laboratoire Cogitamus, 16, route de Gray, 25030, Besançon, France

\section{Colin Petitjean (D)} \\ LAMA, Univ Gustave Eiffel, UPEM, Univ Paris Est Creteil, CNRS, \\ F-77447, Marne-la-Vallée, France
}

\begin{abstract}
Antonín Procházka (if
Laboratoire de Mathématiques de Besançon, Université Bourgogne Franche-Comté, CNRS UMR-6623, 16, route de Gray, 25030, Besançon Cedex, France
\end{abstract}

https://doi.org/10.1017/prm.2020.67, Published online by Cambridge University Press: 08 December 2021

The editors of Proceedings of the Royal Society of Edinburgh Section A: Mathematics have retracted the following article because it was withdrawn from the journal by the authors on 24 September 2020, and its publication in this journal on 8 December 2021 was accidental. Due to an administrative error on the part of the publisher, Cambridge University Press and Assessment, the article was mistakenly published as part of Volume 151 Issue 6 on 8 December 2021.

The article was submitted to and published by the journal Studia Mathematica after its withdrawal from Proceedings of the Royal Society of Edinburgh Section A: Mathematics. The reference details of this article are as follows: Aliaga, Ramón J.; Noûs, Camille; Petitjean, Colin; Procházka, Antonín. Compact reduction in Lipschitz-free spaces. Studia Math. 260 (2021), no. 3, 341-359.

The editors of Proceedings of the Royal Society of Edinburgh Section A: Mathematics and Cambridge University Press and Assessment sincerely apologise to the authors, and to Studia Mathematica for this error. The authors bear no responsibility for the error.

Reference:

Aliaga, R., Noûs, C., Petitjean, C., \& Procházka, A. (2021). Compact reduction in Lipschitz-free spaces. Proceedings of the Royal Society of Edinburgh: Section A Mathematics, 151(6), 1683-1699. doi:10.1017/prm.2020.67

(C) The Author(s), 2022. Published by Cambridge University Press on behalf of The Royal Society of Edinburgh 